\title{
Urban Design and Planning: Referees 2018
}

The following is a list of referees who have reviewed papers for Urban Design and Planning between 1 January 2018 and 30 November 2018. The Institution of Civil Engineers is very grateful for their assistance.

We are continually looking for suitable reviewers for papers submitted to Urban Design and Planning. Papers published in the Proceedings of the ICE must be submitted to at least two independent referees to judge accuracy, style, impact, importance and interest.

If you are interested in reviewing articles on any topic related to urban design and planning, please submit your name, qualifications or CV, and

Yasemin Afacan

Khalid Al-hagla

Natasha Aruri

Anlı Ataöv

Simona Azzali

Henco Bekkering

Felix Bentlin

Carron Blom

Simon Bowers

Andreas Brück

Roger Chan

Annie Chen

Angela Connelly

Martin Crookston

Silvia Dalla Costa

Lili de Larratea

Ozlem Demir
Alan Derbyshire

Donatella Diolait

Denise Duarte

Daniel Durrant

Noah Durst

Nicholas Falk

Yuan Gao

Jorge Gil

John Gold

Melina Guirnaldos Díaz

Gary Hack

Kamonashish Haldar

John Harding

Matthew Hardy

Safak Hengirmen Tercan

Fransje Hooimeijer

Solmaz Hosseinioon

areas of expertise. We are in need of individuals who will agree to review papers in a timely fashion (within 3 to 4 weeks of receipt) and provide confidential feedback to the Editorial Advisory Panel concerning the quality of the paper and any suggested revisions that would be appropriate.

If you are such a person, please contact Abiola Lawal

(tel.: +44 (0)207 665 2249; e-mail: abiola.lawal@ice.org.uk) for more information on the referee process.

lan Jenkinson

Prasanna K

Mike Kagioglou

Aykut Karaman

Mohamad Kashef

Marija Kesic

Willem Korthals Altes

Zeenat Kotval-Karamchandani

Klaus Kunzmann

Yunfei Li

Jasna Mariotti

Pedro Martinez-Vazquez

Han Meyer

Angela Million

Nabil Mohareb

Paula Morais

Daniel O'Hare
Derya Oktay

Susan Parham

Mohammad Radfar

Paulo Ribeiro

Yodan Rofe

Maria Rosa

Jon Rowland

Mark Sheppard

Nan Shi

Ajit Singh

Graham Smith

John Thomson

Debabardhan Upadhyaya

Koray Velibeyoglu

Qingping Zhang

Longbin Zhu 